\title{
13 .
}

\section{Preservando a Memória das Pedras}

\section{Hugo Aluai Sampaio, Ana M. S. Bettencourt, Manuel \\ Santos-Estévez, José Moreira, Henrique Cachetas \& \\ Aléssia Barbosa}

\section{Resumo:}

Para as comunidades do passado o mundo "físico" seria entendido como cheio de propriedades significantes. No seguimento dos trabalhos de Ingold (2000), Bradley (2000, 2009), ou Scarre (2009), o que hoje vemos como material inerte seria considerada "viva". Essa será a presente perspetiva de abordagem. Certos afloramentos naturais estão associados a lendas ou crenças muitas vezes ligadas a criaturas mágicas ou estranhas "habitando" no seu interior ou "vivendo" entre eles o que, em muitos casos, converge na determinação de um lugar com denominação. Tal como as pessoas, os afloramentos podem ser vistos como entidades que podem e fazem a diferença, atuando como agentes que corporizam significados e histórias (Tilley, 2002, 2004), consequentemente passados ao longo de gerações.

Durante a Pré-História alguns afloramentos foram gravados com motivos; outros, pela sua forma peculiar ou estranha, formaram parte de mitos históricos e de folclore. Em ambos os casos os afloramentos funcionaram como contentores de memória.

Pretende-se focar a importância da fotogrametria e do registo tridimensional deste tipo de património cultural (frequentemente em risco de destruição), mostrando o potencial desta ferramenta na inventariação e no estudo deste tipo de lugares de memória.

Muitos casos de estudo apresentados foram objeto de análise em diferentes projetos, desenvolvidos de acordo com metodologias da Arqueologia e Antropologia Cultural aplicadas ao Noroeste da Ibéria.

Este tipo de trabalho é fundamental tendo em conta a interpretação e o entendimento do papel dos afloramentos para as sociedades humanas e o seu contributo para a construção das paisagens pré-históricas e presentes. 
Palavras-chave: fotogrametria; afloramentos; sociedades pré-históricas e pré-modernas; gravuras; "folclore".

\begin{abstract}
:
To past and pre-modern societies "physical" world was full of significant properties. Following the works of Ingold (2000), Bradley (2000, 2009), Gosden (2009), or Scarre (2009), what today is seen as inert matter was considered "alive", and that should be the present perspective. Certain natural outcrops are attached to legends and beliefs often referred to magical or odd creatures "inhabiting" inside or "living" within them, and the majority is linked to place-names. Like people, outcrops can be seen as entities that can and make difference, acting as agents that embody meanings and stories (Tilley, 2002, 2004) subsequently passed over generations.

During Prehistory some outcrops were engraved with motifs; others, by their odd or peculiar forms, formed part of historical myths and folklore. In both cases outcrops worked as memory containers.

It is pretended to focus on the importance of photogrammetry and tridimensional record of this kind of cultural heritage (frequently in risk or destruction) and to show the potential of this tool in matters of inventory and study of these places of memory.

Several case studies presented were matter of analysis in different projects and developed according to archaeological and cultural anthropology methodologies applied to the Northwest of Iberia.

This type of work is fundamental to achieve rock art interpretations and to understand the role of outcrops to human societies and their contribution to the construction of prehistoric and present landscapes.
\end{abstract}

Keywords: photogrammetry; outcrops; pre-historic and pre-modern societies; engravings; "folklore".

\title{
Introdução
}

Mas, conquanto a maioria do "mundo religioso" se preocupa em odiar e desprezar as crenças dos pagãos cujas regiões no globo estão marcadas como pontos negros nos mapas missionários, sobra-lhes pouco tempo ou capacidade para as tentar entender.

Edward B. Tyler (1871: 380)

Contrariamente à grande maioria das populações modernas, o mundo físico nem sempre foi visto como um simples invólucro ou contentor de "coisas" inanimadas, senão como algo repleto de significados e sentidos. Assim, e de acordo com os trabalhos de diversos autores (Sahlins, 1972; Ingols, 2000, 2006; Bradley, 2000, 2009; Gosden, 2009; 
Scarre, 2009; Thomas, 2001; Tilley, 2002, 2004), o que hoje vemos, de forma distanciada, como algo aparentemente inerte - seja um penedo, um caminho, ou o topo de uma montanha - foi, outrora, considerado espaço animado. O recurso recorrente a poderes sobrenaturais e a creditação de atributos a "coisas" inanimadas, dada a relação de paridade estabelecida entre "Humanos" e "Natureza", poderá explicar, pelo menos em parte, tal forma de "ver o mundo". É conhecido, em muitas sociedades, o elo estabelecido entre certos lugares naturais e certos poderes sobrenaturais (Bradley 2000). Talvez por isso alguns destes lugares preservem lendas, mitos e crenças, como a presença de seres estranhos ou mágicos vivendo dentro ou entre as rochas. Não será de estranhar, então, que determinados afloramentos possam ancorar uma cosmogonia e significância espiritual que os torna capazes de atuar como agentes sociais poderosos por si só, carácter tantas vezes reforçado pela presença de topónimos, nomes ou designações. São, portanto, lugares de memória importantes no âmbito da estruturação das sociedades, dado o seu impacto na manutenção ou mudança de determinadas práticas, promovendo a lembrança ou, simplesmente, incentivando o seu esquecimento (Halbwachs, 1925/1975, 1950/1992; Connerton, 1989; Hutton, 1993; Van Dyke \& Alcock 2003).

É no âmbito destas premissas que enquadramos o estudo dos afloramentos gravados, uma das principais materialidades que o arqueólogo dispõe para interpretar a memória cultural do passado, partindo das premissas de que os signos gravados, a forma do afloramento escolhido para ser gravado e a sua localização no espaço resultam de um pensamento simbólico e, por consequência, permitem aproximações à estrutura simbólica e à visão cosmogónica que as comunidades tinham do mundo onde estavam incorporadas.

São, ainda, importantes meios de comunicação e de gestão identitária ou, na perspetiva de Ingold (2000), lugares onde a mensagem dos signos constitui um meio de gestão para preservar a contínua "construção" do mundo em que se habita. Talvez por esse motivo tenham sido gravados na pedra, de forma duradoura, para perpetuarem para a posteridade. Nesse sentido, terão sido cenários de significação e de ação, importantes no âmbito da estruturação das sociedades e na transmissão dos seus valores e modos de vida para o futuro. O carácter dourador e visível destes lugares (verdadeiros repositórios de memórias), na sua longa duração, terá proporcionado adições e sobreposições de signos, como formas de consolidação ou alteração das mensagens originais ou de manutenção ou mudança de determinadas práticas sociais. Dito de outro modo, terão sido lugares reconstruídos, reinventados, reinterpretados ou mesmo manipulados. Assim, os afloramentos e as suas formas não se mostram apenas como 
simples superfícies, mas como agentes ativos capazes de acrescentar sentidos e significados e incorporar histórias passíveis de serem passadas de geração em geração. A natureza da arte rupestre em estudo, efetuada ente 6000 e 3000 mil anos, torna difícil a sua visualização e consequente interpretação. Muitas gravuras foram efetuadas com incisões ou picotados poucos profundos, sendo, portanto, pouco percetíveis com luz diurna; outras encontram-se muito erodidas devido à natureza das superfícies geológicas onde foram gravadas, à sua localização e aos agentes erosivos subaéreos a que estão sujeitas; e outras estão em mau estado de conservação, mercê da ação, essencialmente, do fogo, um dos principais fatores da sua destruição.

Nestas circunstâncias, coloca-se o problema de como preservar estes memoriais do passado. Uma das soluções, entre outras ${ }^{1}$, passa pela aplicação de novas tecnologias de informação no seu registo, o que facilita a leitura das gravuras representadas e constitui uma modalidade de exploração não intrusiva capaz de salvaguardar a integridade do património cultural sujeito a observação e estudo, sendo a sua aplicabilidade rápida e de baixo custo².

\section{Objetivos e metodologia}

Recorrendo ao uso de novas tecnologias, o presente trabalho pretende enfatizar a importância da fotogrametria e do registo tridimensional na inventariação, descrição e estudo dos afloramentos gravados como forma de arquivar as mensagens coletivas das sociedades pretéritas e de atingir a sua consequente interpretação.

Pretende-se, igualmente, mostrar o potencial desta ferramenta no processo de musealização e de patrimonialização de alguns destes lugares de memória, não apenas numa perspetiva turística como, também, lúdico-didática.

No âmbito dos diferentes projetos de investigação desenvolvidos por vários autores deste trabalho, que têm contribuído para o estudo da arte rupestre do Noroeste português, houve diferentes etapas metodológicas. Primeiro, optou-se pela inventariação, através do preenchimento de uma ficha pré-definida que alimentou uma base de dados, parcialmente disponível online, desde outubro de 2014 , sob a sigla CVARN, Corpus Virtual de Arte Rupestre do Noroeste Português (www.cvarn.org). Esta base de dados conta já com mais de quatrocentas entradas que incluem a descrição física da envolvente e dos próprios afloramentos gravados e faculta, na grande maioria

\footnotetext{
${ }^{1}$ Referimos, por exemplo, o decalque sobre plástico polivinilo, com canetas de acetato, técnica importante para registar sobreposições, observação de técnicas de fabrico, embora muito mais morosa do que a utilização das novas tecnologias digitais.

2 Já a aplicação do laser scanning ao levantamento das gravuras rupestres é extremamente caro, pelo que se justifica, apenas, em circunstâncias muito específicas.
} 
dos casos, o registo gráfico complementar, assim como referências bibliográficas, quando disponíveis, para cada um dos sítios (Bettencourt, Abad-Vidal \& Rodrigues 2017). Numa segunda etapa, foram selecionados alguns lugares gravados para estudo pormenorizado, onde se efetuaram limpezas das superfícies gravadas e decalques dos motivos através da utilização de plástico polivinilo e de canetas de acetato, técnica muito útil, mas extremamente morosa e, por conseguinte, acarretando maiores custos económicos. Além disso, há determinadas circunstâncias em que esta metodologia se torna difícil ou impossível de utilizar, como é o caso de afloramentos estalados pela ação do fogo que, pela fragilidade que apresentam, não devem ser pisados, sob pena de se inviabilizar qualquer possibilidade de restauro.

Por estes motivos optou-se, posteriormente, pelo levantamento fotogramétrico sistemático das gravuras rupestres, tecnologia que permite a sua reprodução virtual mediante a utilização de dois programas informáticos. Ainda que existam no mercado outras opções com a mesma finalidade, o presente estudo recorre ao Agisoft PhotoScan e ao Meshlab. O primeiro software permite o processamento fotogramétrico de imagens digitais, gerando modelos tridimensionais. Está amplamente disseminado em áreas como a Arquitetura e no estudo da Escultura, mas tem cada vez mais adeptos no seio da Arqueologia, onde tem sido usado no levantamento de abrigos ou de arte rupestre (entre outros, veja-se Rogerio Candelera, 2008; Cabrelles López \& Lerma García, 2013; Lerma García, Cabralles López, Navarro Tarín \& Segui Gil, 2013; Kipnis, Santos, Tizukal, Almeida \& Corga, 2013; Ruiz Sabina, Gutiérrez Alonso, Ocaña Carretón, Farjas Abadía, Domínguez Gómez \& Gómez Laguna, 2015).

Já o MeshLab fornece um conjunto de ferramentas de edição, limpeza, recuperação e conversão de modelos tridimensionais, atingindo melhoramentos através do uso de diferentes tonalidades nas superfícies convexas e côncavas, neste caso, dos afloramentos modelados através do Agisoft Photoscan.

Uma das finalidades deste registo tridimensional é que, num futuro não muito distante, seja anexado à base de dados já existente dedicada à arte rupestre do Noroeste português (CVARN). Só dessa forma a compilação deste arquivo de imagens enquanto tecnologia de leitura da memória adquirirá especial preponderância.

\section{A aplicação prática da fotogrametria à arte rupestre: casos de estudo}

Serão, em seguida, apresentados alguns exemplos da aplicação destas tecnologias a casos concretos de afloramentos com arte rupestre, com resultados, por vezes, surpreendentes. Entre os casos de estudo figuram os sítios de Santo Adrião (freguesia de Âncora, concelho de Caminha), Costa da Areira 2 (freguesia de Sanfins, concelho de 
Valença), Breia 5 (freguesias de Cardielos e Serreleis, concelho de Viana do Castelo), Penedo de S. Gonçalo (freguesia da Varziela, concelho de Felgueiras) e Penedos Gordos (freguesia de Aldreu, concelho de Barcelos).

Em Santo Adrião, um lugar composto por um vasto caos de blocos graníticos (Figura 1), muitos deles gravados (Santos-Estévez \& Betencourt, 2017), destaca-se a rocha 1 que inclui a representação de duas armas da Idade do Bronze Inicial e Médio (fins do $3^{\circ} \mathrm{e}$ $2^{\circ}$ milénios a.C.) em associação (uma alabarda e uma espada).

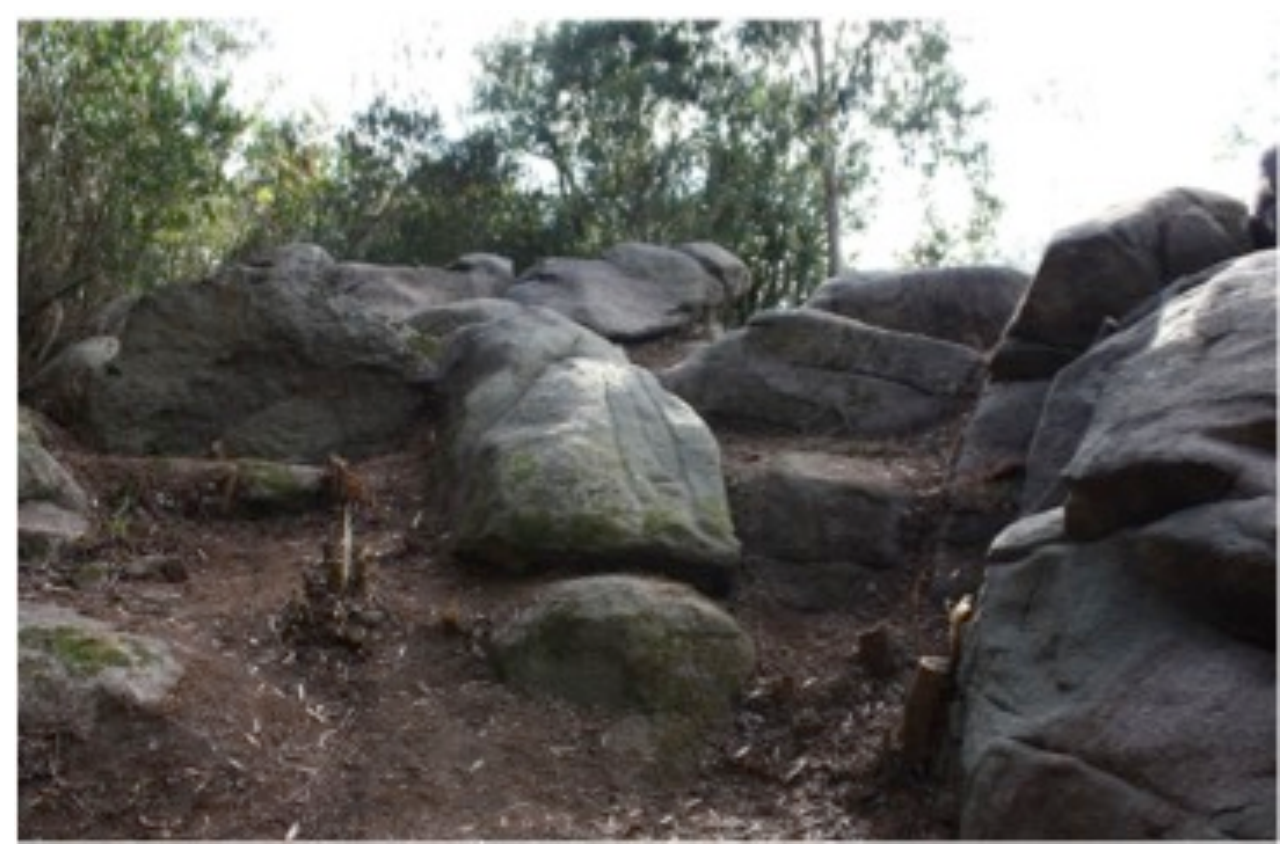

Figura 1. Caos de blocos graníticos, alguns dos quais gravados, de Santo Adrião (Âncora, Caminha).

Apesar de serem signos realizados com sulcos de alguma profundidade, a comparação entre a fotografia digital e o levantamento fotogramétrico mostra que esta metodologia introduz um grande detalhe na visualização e no registo dos motivos gravados, além de proporcionar dados sobre a inclinação do afloramento e sobre a distribuição dos motivos na superfície rochosa (Figura 2). 

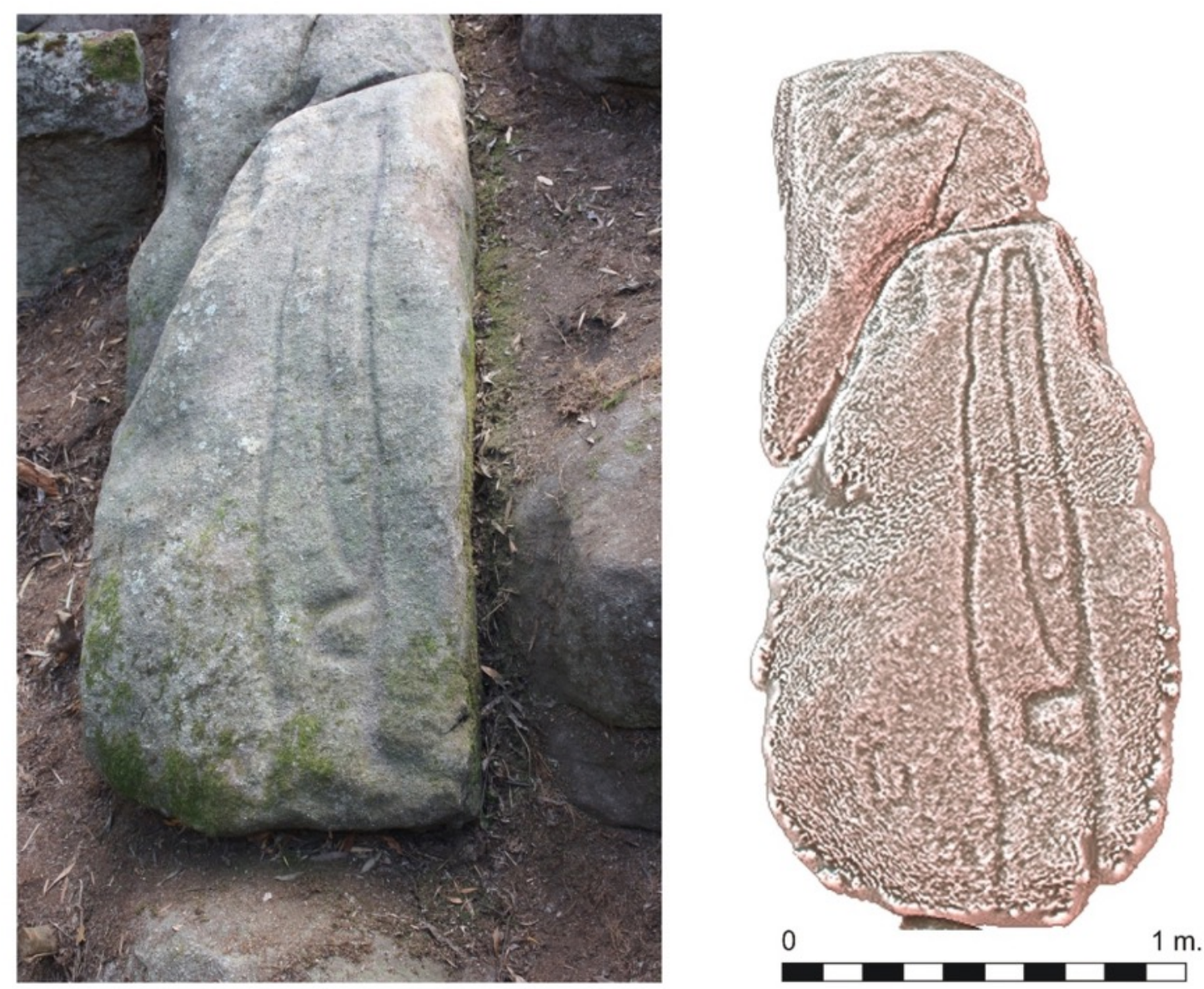

Figura 2. Comparação entre fotografia digital da rocha 1 de Santo Adrião, que inclui a representação de uma alabarda e de uma espada em associação, com respetivo levantamento fotogramétrico.

Na Costa da Areira 2, um afloramento também gravado com armas da Idade do Bronze Inicial (fins do $3^{\circ}$ e inícios do $2^{\circ}$ milénio a.C.) (Santos-Estévez, Bettencourt, Sampaio, Brochado \& Ferreira, 2017), a utilização da fotogrametria é um exemplo de como a aplicação desta tecnologia pode surpreender. Sabia-se, após atenta observação com luz diurna e luz artificial rasante, efetuada durante a noite, que o afloramento tinha gravado um conjunto de covinhas, no seu topo, e duas alabardas encabadas, na pendente (Figura 3). 


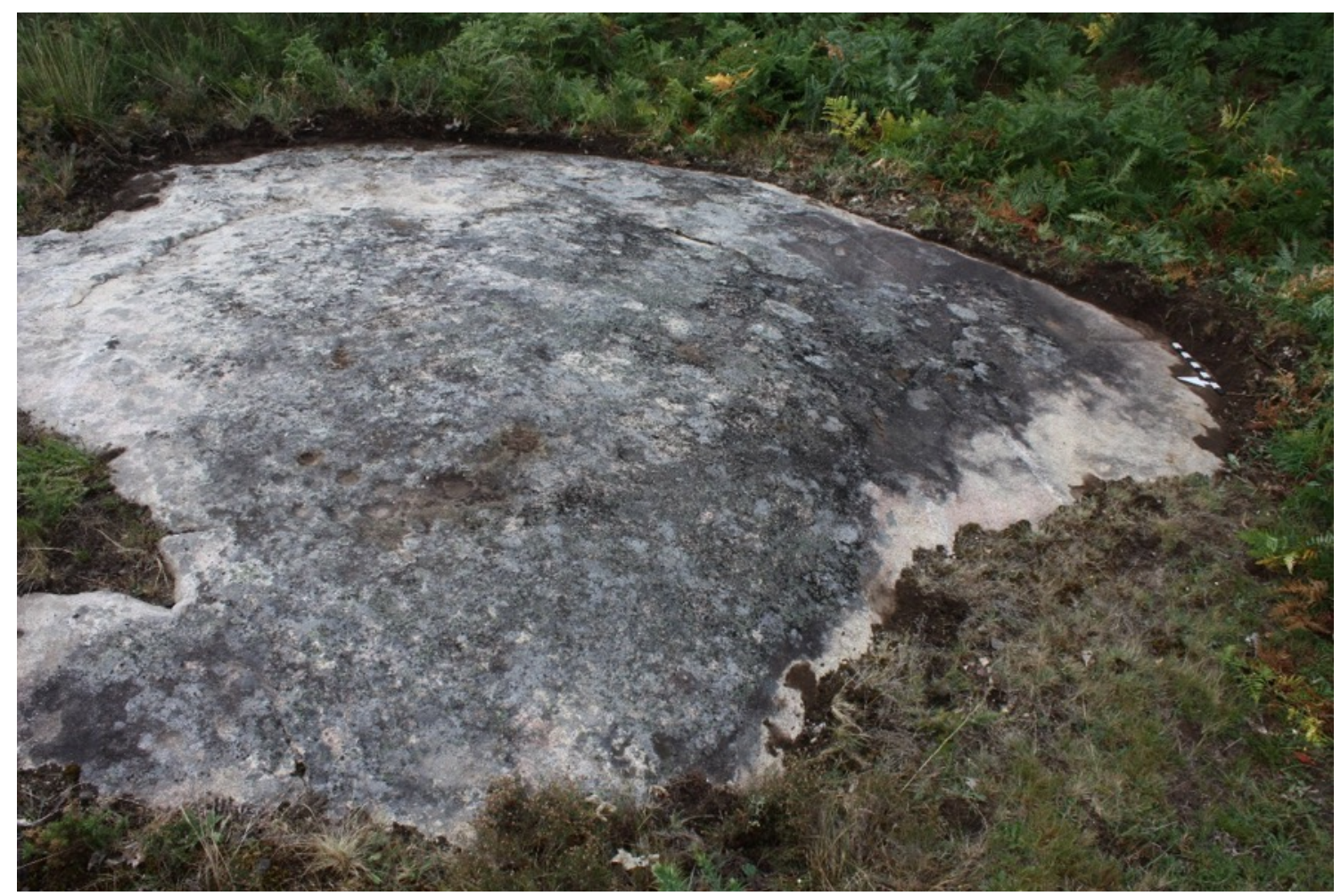

Figura 3. Afloramento gravado de Costa da Areira 2 (Sanfins, Valença) em fotografia digital a partir de Noroeste

Dada a pouca profundidade das gravuras, a aplicação das novas tecnologias descritas possibilitou a descoberta de uma terceira alabarda, de pequeníssimas dimensões (Figura 4).

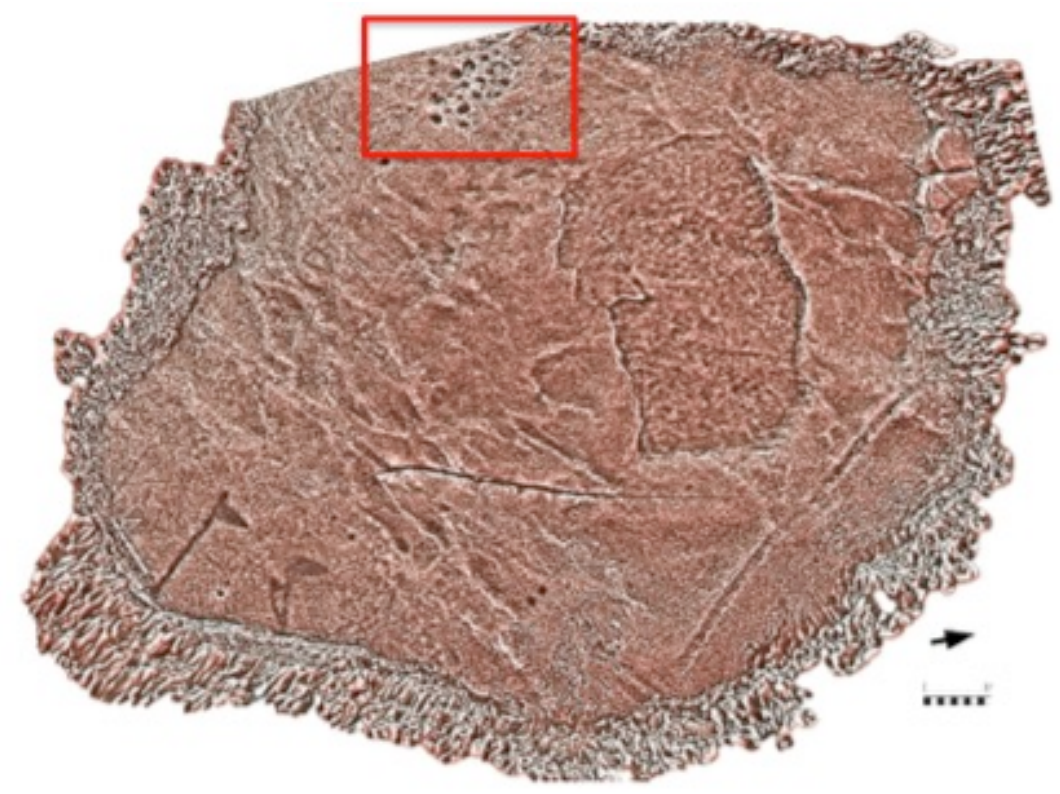

Figura 4. Levantamento fotogramétrivo do afloramento gravado de Costa da Areira 2. 
A Breia 5, parte integrante de um complexo mais extenso de rochas gravadas localizadas nas vertentes este e sudeste do Monte de São Silvestre, inclui a representação de diversos quadrúpedes, nomeadamente equídeos, entre outros motivos, provavelmente de cronologia proto-histórica (Idade do Bronze ou do Ferro). As dimensões do afloramento atingem os 13 metros de comprimento por 4 metros de largura, sendo este destacado do solo. A ação de fogos recentes levou à degradação de grande parte da superfície deste afloramento, provocando inúmeros estalamentos, a destruição irreversível de alguns motivos e dificultando a visualização de outros (Figura $5)$.

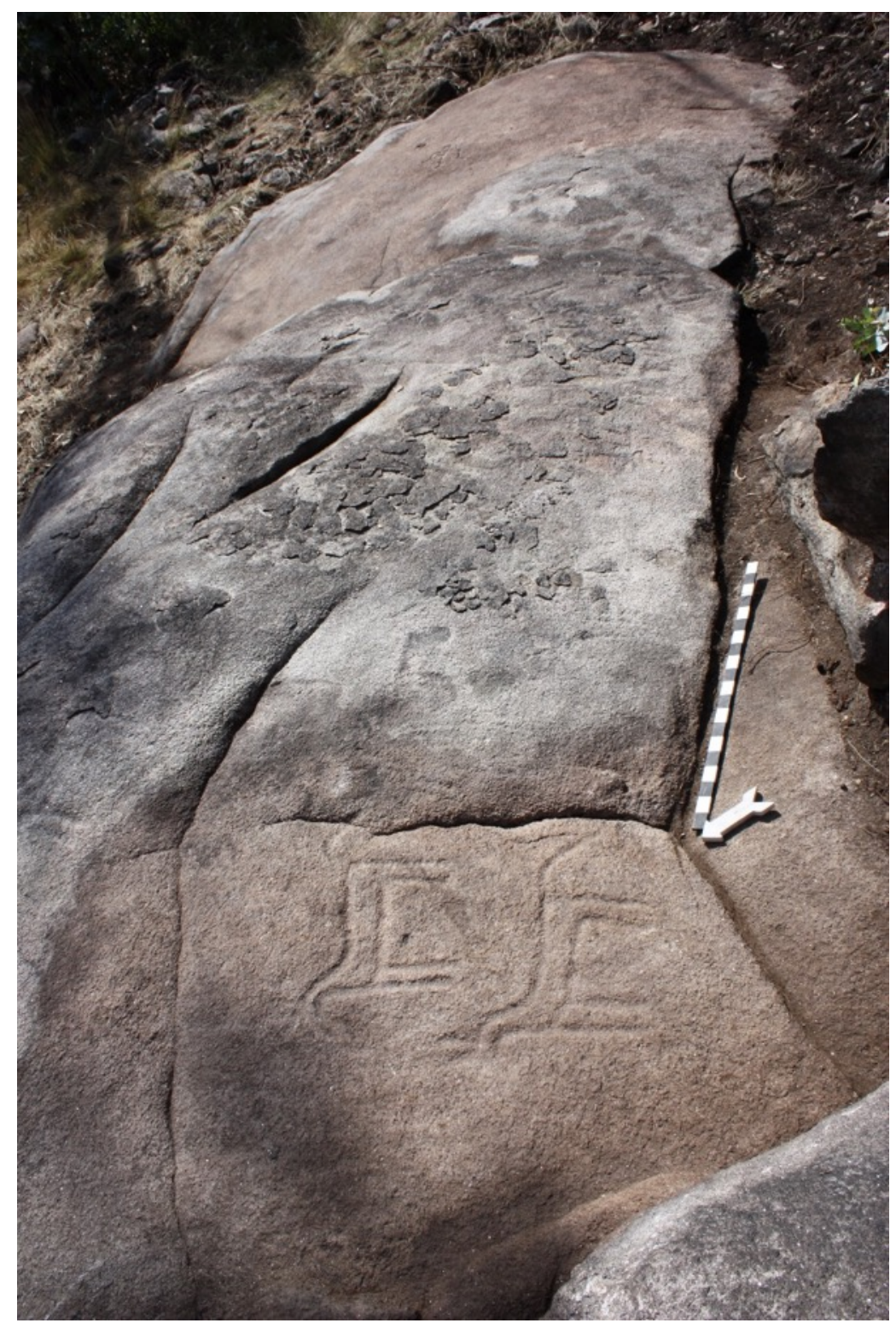

Figura 5. Rocha gravada de Breia 5 (Cardielos e Serreleis, Viana do Castelo) com equídeos com presença de diversos estalamentos originados pelo fogo.

Neste caso era impossível a aplicação do levantamento dos motivos por plástico polivinilo pois o contacto com a superfície rochosa seria o suficiente para aumentar a 
sua deterioração. Assim, a aplicação das metodologias descritas possibilitou efetuar o levantamento dos motivos gravados e identificar alguns quadrúpedes que não se conseguiam detetar macroscopicamente, conforme se pode observar na representação do quadrúpede marcado com o retângulo, cujo corpo se encontra parcialmente em falta (Figura 6).

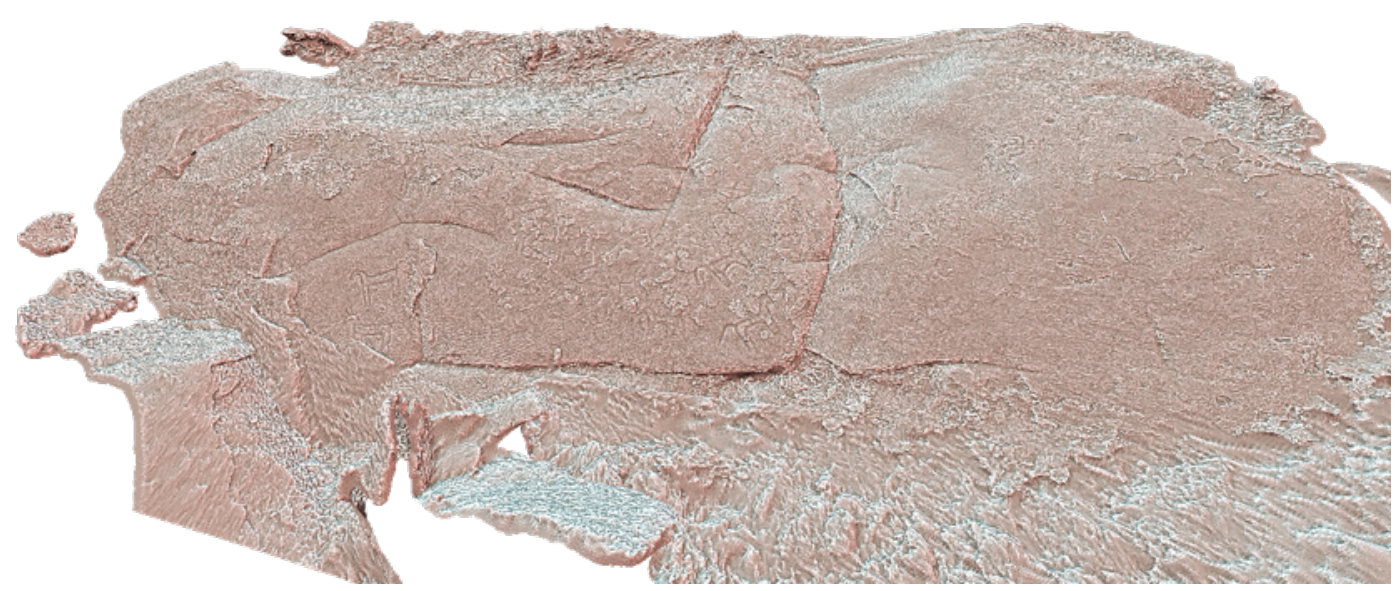

Figura 6. Levantamento fotogramétrico de Breia 5 com representações de equídeos identificadas mesmo entre os estalamentos

O Penedo de S. Gonçalo, um grande bloco granítico em estudo por um dos subscritores deste artigo (J.M.), encontra-se profusamente gravado no topo e em duas das suas pendentes com motivos que vão desde a arte atlântica (Neolítica $-4^{\circ}$ milénio a.C.) até cavalos esquemáticos, podomorfos e artefactos, de cronologia proto-histórica (Moreira, Bettencourt \& Santos-Estévez, 2016) (Figura 7). 


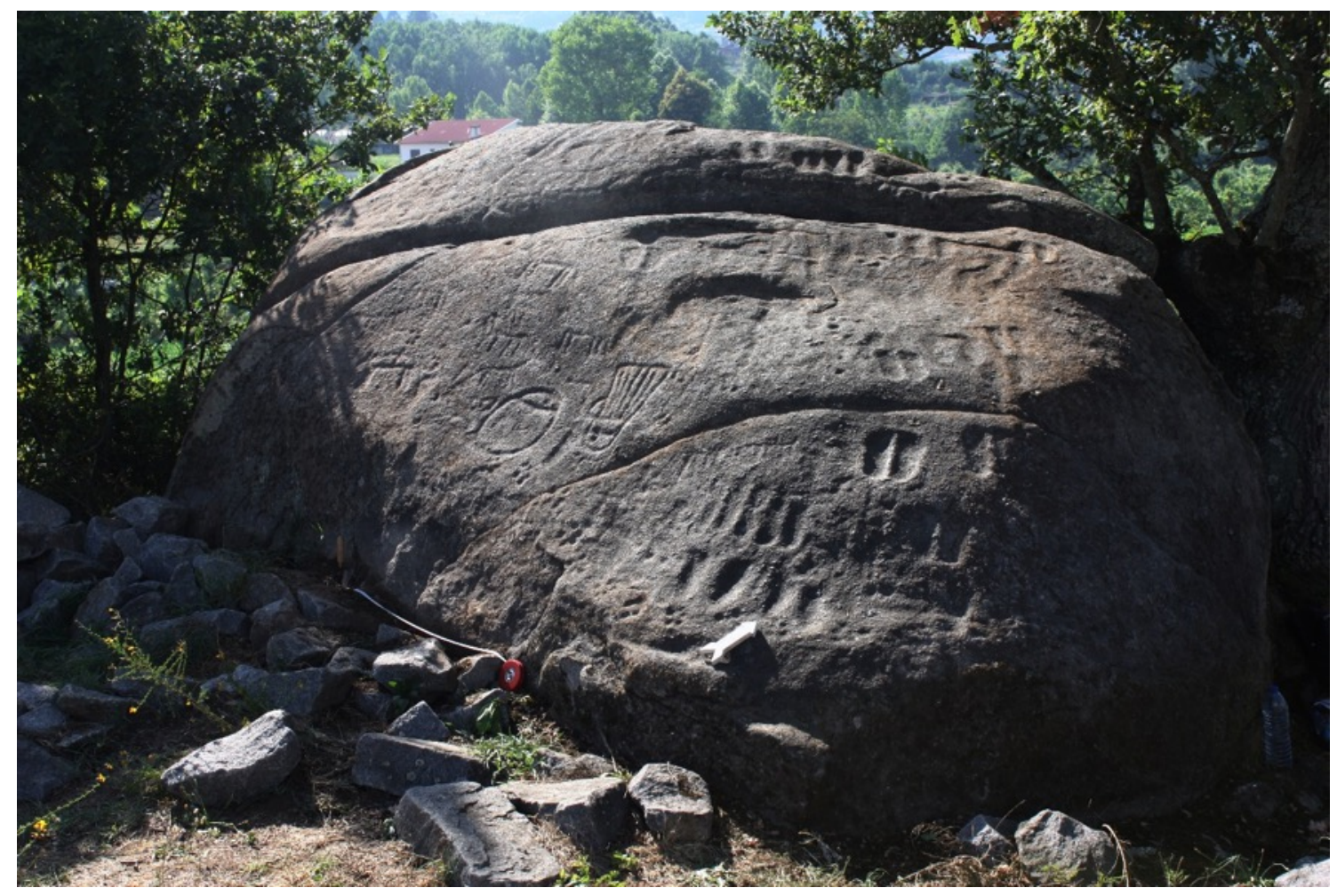

Figura 7. Vista geral da rocha gravada de S. Gonçalo (Varziela, Felgueiras) em fotografia digital efetuada a partir de Sudeste

Ainda que alguns dos motivos se encontrem bem sulcados, o levantamento fotogramétrico permitiu identificar inúmeros quadrúpedes esquemáticos, alguns cavaleiros e diversos podomorfos, principalmente na superfície superior, área onde os motivos se encontravam mais erodidos (Figura 8).
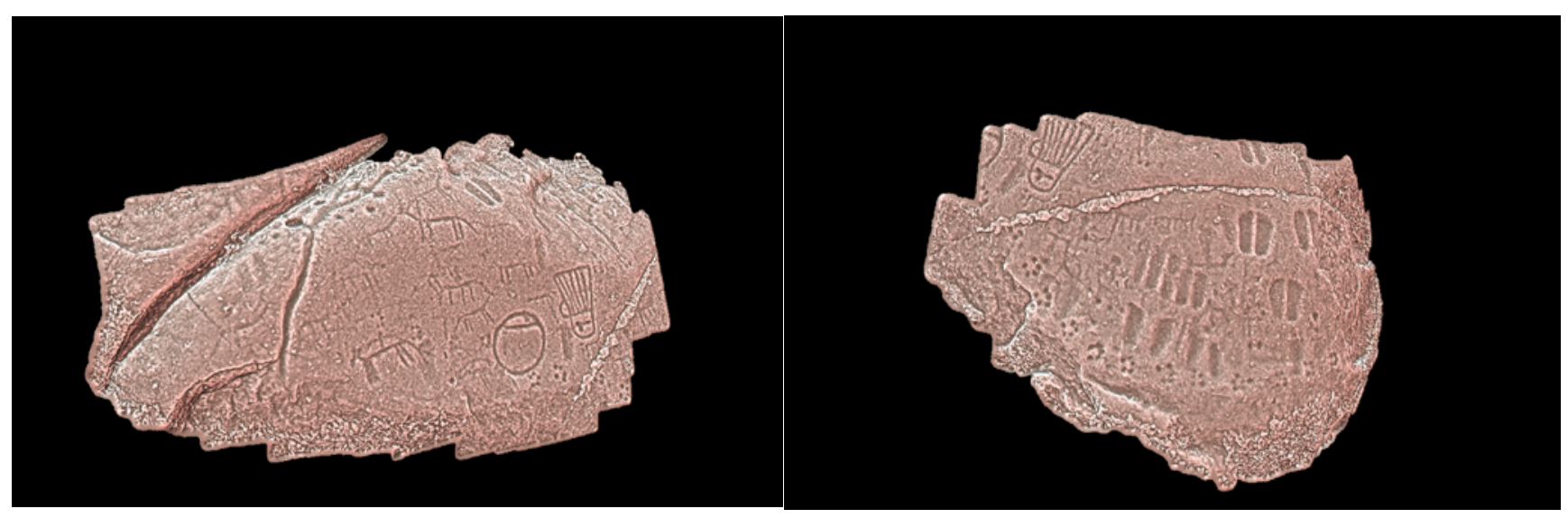

Figura 8. Levantamento fotogramétrico da rocha de $\mathrm{S}$. Gonçalo: à esquerda, painel 1; à direita, painel 2

Um caso particularmente interessante foi o verificado nas vertentes do Monte de S. Gonçalo, em Barcelos. Após a identificação do primeiro afloramento gravado, em 2012, foram descobertos, até à data, um total de 43 afloramentos gravados. Tal concentração 
torna o Monte de S. Gonçalo num dos complexos de arte rupestre mais significativos do Noroeste português. A par da quantidade de gravados, a curiosidade reside no fato de muitos dos afloramentos gravados terem sido identificados após o seu tratamento fotogramétrico. Ou seja, muitos afloramentos indiciavam conter gravuras, mas as dúvidas só foram esclarecidas após o seu tratamento fotogramétrico e posterior trabalho em laboratório. Dá-se aqui o exemplo do Penedo Gordo (Aldreu, Barcelos), onde se destaca uma composição esquemática denunciando movimento, a qual inclui um cervídeo e um antropomorfo associado a um arco e flecha, além de diversas composições circulares inseríveis na arte atlântica e no período Neolítico ( $4^{\circ}$ milénio a.C.) que, por se encontrarem muito erodidas, eram de difícil visualização (Figura 9).

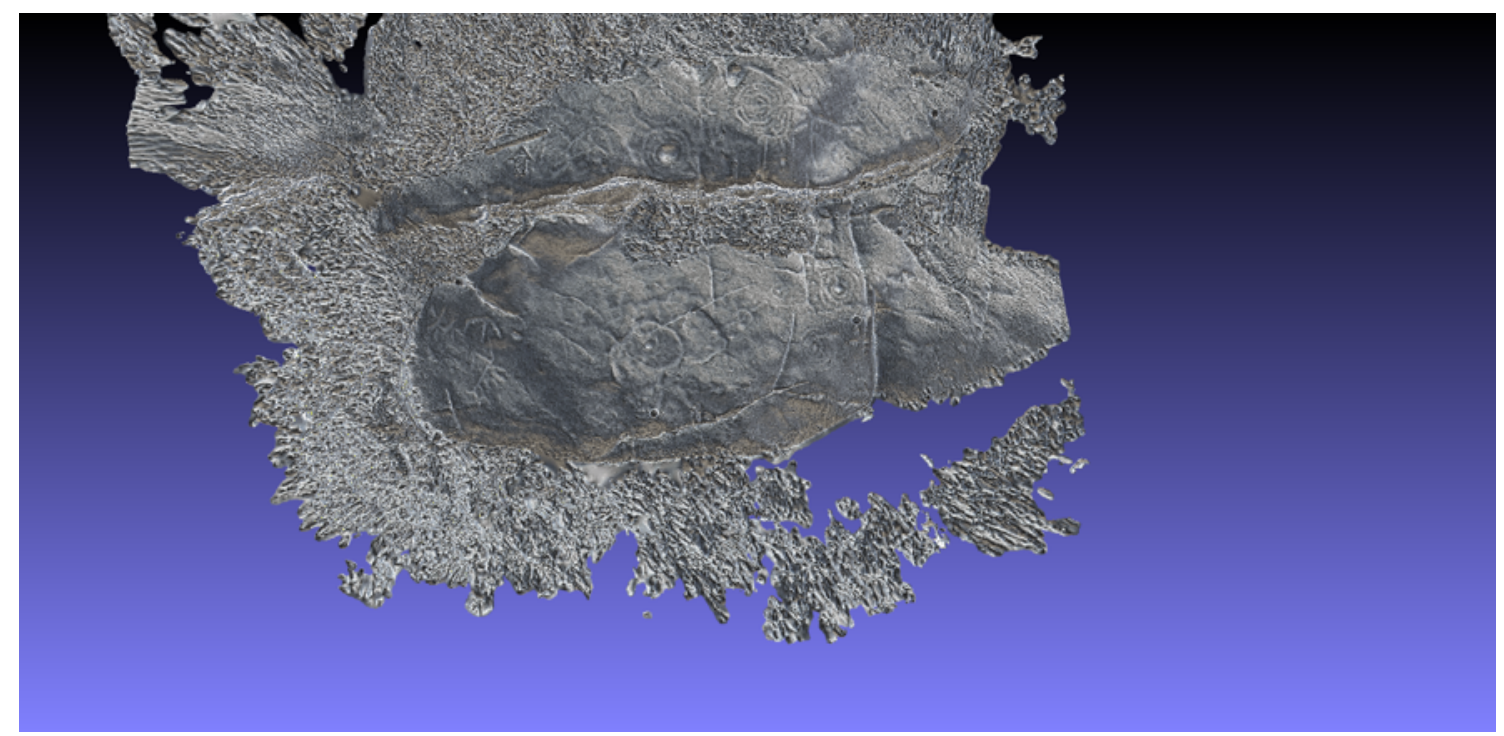

Figura 9. Levantamento fotogramétrico da rocha gravada de Penedos Gordos (Aldreu, Barcelos) com representações circulares e um antropomorfo associado a um arco e flecha

\section{Algumas considerações finais}

Em primeiro lugar pode ser referido que a aplicação da fotogrametria como arquivo de memória é essencial porque permite, não apenas observar melhor uma realidade difícil de detetar macroscopicamente, mas porque é, também, uma modalidade prospetiva não evasiva que respeita a integridade dos locais em estudo.

Em segundo lugar, note-se que esta tecnologia concede o levantamento deste (e de outros) tipo(s) de património, levantamento esse que será tanto mais completo quanto mais exaustivo for o registo fotográfico efetuado e a qualidade da resolução do mesmo. Ou seja, levantamentos fotográficos exaustivos e de maior definição permitem modelos tridimensionais mais apurados e de maior pormenor. Além disso, a "informação" gerada 
é passível de ser posteriormente arquivada em formato 3D, cuja leitura é distinta da planimétrica, algo que adiante veremos ter as suas vantagens.

Paralelamente, a aplicação destas tecnologias promove a preservação de traços de identidade e de memória, mesmo nos casos em que ocorra a destruição física dos suportes (neste caso, dos afloramentos), independentemente dessa destruição ter uma origem natural ou antrópica.

Ao mesmo tempo, incentiva novas interpretações da arte rupestre, cujos significados e propósitos serão sempre difíceis de atingir. Tal é deveras importante porque muitos são os casos onde parece haver uma clara relação entre o posicionamento dos motivos e a morfologia dos afloramentos gravados, associando-se a protuberâncias, a diaclases, a veios de quartzo, etc. Estas relações serão certamente melhor estabelecidas com recurso a um modelo tridimensional, contrariamente aos clássicos levantamentos bidimensionais.

Em terceiro lugar, todo o "registo" criado é passível de ser acoplado numa base de dados e, com isso, ficar disponível para a comunidade científica ou para outras quaisquer instituições gestoras do património.

Por fim, mas não menos importante, é uma metodologia de rápida exequibilidade em campo, e de baixo custo, o que se adequa bem às crescentes dificuldades económicas sentidas na área da investigação. Deverá ainda ser referido que algum acesso a este tipo de software está facilitado pela disponibilização gratuita, ainda que, conforme sucede com outros produtos, apenas com um número limitado de ferramentas. Ainda que numa versão restritiva, há sempre a possibilidade de gerar modelos que, no caso da Arqueologia, são de valor científico inegável.

A aplicação desta metodologia, com sucesso, aos afloramentos gravados permitiu perceber a sua utilidade quando aplicada a todos os afloramentos significantes - sejam eles portadores de nome, associados a mitos, a lendas e/ou ritos -, apesar de serem já objeto de estudo da Antropologia Cultural. Trata-se de um património em risco que está a ser destruído rapidamente e que urge inventariar e registar. Ressalva-se, contudo, que os afloramentos atualmente significantes no seio das sociedades tradicionais não devem ser tratados como meros casos de estudo, mas como elementos vivos de uma paisagem cultural cujo secretismo do seu posicionamento, forma e mensagem, por vezes, é necessário respeitar. 


\section{Referências bibliográficas}

Bettencourt, A.M.S.; Abad-Vidal, E.; Rodrigues, A. (2017). Cvarn - Rock Art Virtual Corpus of North-western Portugal. A Multimedia tool to investigate and describe PostPalaeolithic Rock Art. In A. M. S. Bettencourt, M. Santos-Estevez, H.A. Sampaio \& D. Cardoso (Eds.), Recorded Places, Experienced Places. The Holocene Rock Art of the Iberian Atlantic Northwest. British Archaeological Reports - BAR, Oxford: Archeopress.

Bradley, R. (2000). An Archaeology of Natural Places. Londres and Nova lorque: Routledge.

Bradley, R. (2009). Dead stone and living rock. In B. O'Connor, G. Cooney \& J. Chapman (Eds.), Materialitas. Working Stone, Carving Identity [Prehistoric Society Research Paper 3] (pp. 1-8). Oxford: The Prehistoric Society/Oxbow Books.

Cabralles López, M. \& Lerma García, J. L. (2013). Documentación 3D de abrigos rupestres a partir de laser escáner y de procesos fotogramétricos automatizados. VAR, 4(8), 64-68.

Connerton, P. (1989). How societies remember. Cambridge: Cambridge University Press.

Feld, S. \& Basso, K.H. (1996). Senses of Place. New Mexico: School of American Research Press.

Gosden, C. (2009). Afterword. In B. O'Connor, G. Cooney, J. Chapman (Eds.), Materialitas. Working Stone, Carving Identity [Prehistoric Society Research Paper, 3] (pp. 181-184). Oxford: The Prehistoric Society/Oxbow Books.

Halbwachs, M. (1925/1975). Les cadres sociaux de la mémorie. Nova lorque: Arno.

Halbwachs, M. (1950/1992). On Collective Memory. Ed. e trad. L.A. Coser. Chicago: University of Chicago Press.

Hutton, P. (1993). History as an Art of Memory. Hanover: University of Vermont Press.

Ingold, T. (2000). The Perception of the Environment: Essays in Livelihood, Dwelling and Skill. Londres: Routledge.

Kipnis, R.; Santos, H.; Tizukal, M.; Almeida, M. \& Corga, M. (2013). Aplicação das tecnologias de modelagem $3 \mathrm{D}$ conjugada às técnicas tradicionais para o registro das gravuras rupestres do rio Madeira, Rondônia, Brasil. Boletim do Museu Paraense Emílio Goeldi. Ciências Humanas, 8 (3): 605-619.

Lerma García, J. L.; Cabralles López, M.; Navarro Tarín, S.; Segui Gil, A. E. (2013). Modelado fotorrealístico 3D a partir de procesos fotogramétricos: láser escáner versus imagen digital. Cuadernos de Arte Rupestre 6: 85-90.

Moreira, J.; Bettencourt, A. M. S.; Santos-Estévez, M. (2016, 30 de novembro). "Penedo de S. Gonçalo (boulder of Saint Gonçalo), Felgueiras, NW Portugal. A long life of a rock art place". Poster apresentado no Simpósio Internacional Images in Stones, Braga.

Rogerio Candelera, M. A. (2008). Una propuesta no invasiva para la documentación integral del arte rupestre. Sevilha: Instituto de Recursos Naturales y Agrobiología de Sevilla (IRNAS). 
Ruiz Sabina, J. A.; Gutiérrez Alonso A.; Ocaña Carretón, A.; Farjas Abadía, M.; Domínguez Gómez, J. A. \& Gómez Laguna, A. J. (2015). Aplicación de la fotogrametría aérea por dron al estudio y documentación del arte rupestre y análisis por medioe digitales: los grabados de la Laguna Tinaja (Lagunas de Ruidera, Albacete) desde un nuevo punto de vista. ARKEOS, 37: 2075-2077.

Santos-Estévez, M. \& Bettencourt, A. M. S. (2017). O conjunto de gravuras rupestres de Santo Adrião (Caminha, Portugal). Embarcações, armas, cavalos e ex-votos. Livro de Actas do II Congresso da Associação dos Arqueólogos Portugueses (pp. 1055-1070). Lisboa: Associação dos Arqueólogos Portugueses.

Santos-Estevez, M.; Bettencourt, A.M.S.; Sampaio, H.A.; Brochado, C.; Ferreira, G. (2017). Shape and meaning: engraved weapons as materialisations of the Calcolithic / Early Bronze Age cosmogony in NW Iberia. In A. M. S. Bettencourt, M. Santos-Estevez, H.A. Sampaio, D. Cardoso (Eds.), Recorded Places, Experienced Places. The Holocene Rock Art of the Iberian Atlantic Northwest (pp. 151-166). British Archaeological Reports - BAR, Oxford: Archeopress.

Sahlins, M. (1972). Stone Age Economics. Chicago: Aldine Atherton Inc.

Salhins, M. (1988). Cosmologies of Capitalism: the TransPacific Sector of "The World System". Proceedings of the British Academy, 74: 1-51.

Scarre, C. (2009). Stones with character: animism, agency and megalithic monuments. In B. O'Connor, G. Cooney, J. Chapman (Eds.), Materialitas. Working Stone, Carving Identity. [Prehistoric Society Research Paper, 3] (pp. 9-18). Oxford: The Prehistoric Society/Oxbow Books.

Thomas, J. (2001). Archaeologies of Place and Landscape. In I. Hodder (ed.) Archaeological Theory Today. Cambridge: Wiley, 165-186.

Thomas, J. (2006). From dwelling to building. In V. O. Jorge, J. Muralha-Cardoso, A. Vale, G. L. Velho, L. Pereira (Eds.), Approaching "Prehistoric and Protohistoric architectures" of Europe from a Dwelling perspective. Porto: ADECAP.

Tilley, C. (2002). Metaphor, materiality and interpretation. In V. Buchli (Ed.), The Material Culture Reader (pp. 23-26). Oxford: Berg.

Tilley, C. (2004). The Materiality of Stone: explorations in Landscape Archaeology. Oxford University Press: Berg.

Tyler, E.B. (1871). Primitive Culture: researches into the development of Mythology, Philosophy, Religion, Art, and Custom. London: John Murray.

Van Dyke, R. M. \& Alcock, S. E. (2003). Archaeologies of Memory: an introduction. In R. M. Van Dyke \& S. E. Alcock (Eds.) Archaeologies of Memory (pp. 1-13). Oxford: Wiley.

Hugo Aluai Sampaio Departamento de Gestão do Instituto Politécnico do Cávado e do Ave; Laboratório de Paisagens, Património e Território. 
Ana M.S. Bettencourt Departamento de História da Universidade do Minho; Laboratório de Paisagens, Património e Território (Lab2pt).

凶anabett@uaum.uminho.com

Manuel Santos-Estévez Bolseiro de Pós-doutoramento da Fundação para a Ciência e Tecnologia; Laboratório de Paisagens, Património e Território (Lab2pt).

\manuel.santos@mundo-r.com

José Moreira Mestrando em Arqueologia na Universidade do Minho.

\zeto_friendfred@hotmail.com

Henrique Cachetas Mestrando em Arqueologia na Universidade do Minho.

$\triangle$ hcachetas@gmail.com

Aléssia Barbosa Mestranda em Arqueologia na Universidade do Minho.

凶alessiad_barbosa@hotmail.com 